\title{
Fused empirical mode decomposition and wavelets for locating combined damage in a truss-type structure through vibration analysis"
}

\author{
Arturo GARCIA-PEREZ ${ }^{1}$, Juan P. AMEZQUITA-SANCHEZ ${ }^{2}$, Aurelio DOMINGUEZ-GONZALEZ ${ }^{2}$, \\ Ramin SEDAGHATI ${ }^{3}$, Roque OSORNIO-RIOS ${ }^{2}$, Rene J. ROMERO-TRONCOSO ${ }^{\dagger 11}$ \\ $\left({ }^{1}\right.$ HSPdigital-CA Telematica-Procesamiento Digital de Señales, DICIS, Universidad de Guanajuato, \\ Carr. Salamanca-Valle km 3.5+1.8, Palo Blanco, 36885 Salamanca, Gto., Mexico) \\ ( ${ }^{2}$ HSPdigital, CA Mecatronica, Facultad de Ingeniería, Campus San Juan del Río, Universidad Autonoma de Queretaro, \\ Moctezuma 249, Col. San Cayetano, 76807 San Juan del Río, Qro., Mexico) \\ $\left({ }^{3}\right.$ Department of Mechanical and Industrial Engineering, Concordia University, 1455 de Maisonneuve Boulevard, \\ West Montreal, QC, H3G 1M8, Canada) \\ †E-mail: troncoso@hspdigital.org \\ Received Jan. 19, 2013; Revision accepted May 19, 2013; Crosschecked Aug. 20, 2013
}

\begin{abstract}
Structural health monitoring (SHM) is a relevant topic for civil systems and involves the monitoring, data processing and interpretation to evaluate the condition of a structure, in order to detect damage. In real structures, two or more sites or types of damage can be present at the same time. It has been shown that one kind of damaged condition can interfere with the detection of another kind of damage, leading to an incorrect assessment about the structure condition. Identifying combined damage on structures still represents a challenge for condition monitoring, because the reliable identification of a combined damaged condition is a difficult task. Thus, this work presents a fusion of methodologies, where a single wavelet-packet and the empirical mode decomposition (EMD) method are combined with artificial neural networks (ANNs) for the automated and online identification-location of single or multiple-combined damage in a scaled model of a five-bay truss-type structure. Results showed that the proposed methodology is very efficient and reliable for identifying and locating the three kinds of damage, as well as their combinations. Therefore, this methodology could be applied to detection-location of damage in real truss-type structures, which would help to improve the characteristics and life span of real structures.
\end{abstract}

Key words: Truss structure, Vibration, Spectral analysis, Wavelet packet transform, Empirical mode decomposition, Artificial neural network (ANN)

doi:10.1631/jzus.A1300030

Document code: A
CLC number: O34

\section{Introduction}

With the worldwide increase of new civil infrastructure, developing novel sensing equipment for improved damage identification systems is necessary. As such, structural health monitoring (SHM) has become an important topic for civil and mechanical

\footnotetext{
Corresponding author

* Project (No. PIFI-2012 U. de Gto.) supported by the Secretariat of Public Education (SEP), Mexico

(C) Zhejiang University and Springer-Verlag Berlin Heidelberg 2013
}

engineering research, because it allows for the analysis of the behavior of a structural system in order to help preserve the structural performance during its years of service. SHM consists of implementing a damage identification system that involves the monitoring, data processing, and interpretation, to evaluate the condition of a structure with the aim of detecting damage early and to make the corresponding maintenance decisions that will be useful for preventing the fall or collapse of structures, while avoiding human and economic losses (Doebling 
et al., 1998; Yang and Sun, 2011; Baptista et al., 2012). In general, to detect damage in a structure, a comparison between two different conditions of the structural system is necessary: the initial state representing the healthy condition of the structure, and the actual condition, which should be assessed as healthy or damaged (Farrar and Worden, 2007).

In particular, many SHM methods based on modal parameters have been used for the detection and location of damage in structures. The basic idea of these methods is that modifications to structural dynamic characteristics affect the modal parameters of a structure, such as natural frequencies (Wang et al., 2001; Hao and Xia, 2002; Chen et al., 2005; Sayyad and Kumar, 2011), mode shapes (Hao and Xia, 2002), damping ratios (Curadelli et al., 2008) or their derivatives (Wang and Chen, 2005) (e.g., flexibility matrices, curvature mode shapes, etc.). The main goal of this method is to find dynamic characteristics, which are sensitive to not only damage but also to environmental conditions such as humidity, wind, and temperature. Therefore, before using the modal parameters to detect damage, it is necessary to consider changes in environmental conditions. Several researchers have proposed various methodologies to compensate for the effects of temperature (Cornwell et al., 1999; Peeters and de Roeck, 2001; Ko et al., 2003; Meruane and Heylen, 2012). For example, Cornwell et al. (1999) proposed a linear regression model to describe the variations of natural frequencies caused by the changes of temperature in a bridge. Peeters and de Roeck (2001) reported a methodology based on an autoregressive model with exogenous inputs (ARX) model to detect variation in the natural frequencies caused by the temperature changes in a bridge. Despite promising results to compensate for the effects of environmental conditions, the problem has not been resolved. For this reason, it would be desirable to establish a more practical and effective damage identification approach, which allows for the creation of a methodology to identify and localize the damage in the structure.

Damage suffered by civil structures during their service life can be attributed to several reasons such as excessive movements, corrosion, high temperature, cumulative crack growth, degradation of columns, joints, beams, and the impact produced by a foreign object (Umesha et al., 2009). Truss-type structures are widely employed in the design of civil infrastructure because of their easy assembling and material savings when compared to other types of structures, their ability to span across long distances with limited sag, their quick installation, their lightweight, and accessible space provided for maintenance. Thus, truss-type structures play an important role in many applications such as bridges, towers, cranes, roof supports, building skeletons, etc. (Yan et al., 2012). Several investigations to identify damage in these kinds of structures have been proposed; unfortunately, most of them deal with identifying just one damage or isolated damage. In real life, truss-type structures can be affected by several damage such as loosening of bolted connections (Mehrjoo et al., 2008; Yan et al., 2012), cracks (Jiang et al., 2012; Xiang and Liang, 2012), missing elements (Taha, 2010), reduced stiffness (RS) (Law et al., 2005; Lei et al., 2012), and corrosion (Batis and Rakanta, 2005; Osornio-Rios et al., 2012). Moreover, in a real structure, two or more types of damage can be present at the same time, and it has been shown that one kind of damaged condition can interfere with the detection of another kind of damage, leading to an incorrect assessment about the structure condition (Yan et al., 2012). Identifying combined damage on structures still represents a challenge for condition monitoring; they have rarely been considered despite being a common situation, because the reliable identification of a combined damaged condition, considering the presence of two or more kinds of damage, is a difficult task.

Visual or experimental localization procedures are currently used in SHM. Some of these procedures are: the acoustic emission ( $\mathrm{Li}$ et al., 2011), infrared thermography (Shih et al., 2000), ultrasound (Voigt et al., 2003), image processing (Nishikawa et al., 2012), eddy currents (Banks et al., 2002), and radiographs (Vossoughi et al., 2007); which are all used in assessing structural damage. However, the aforementioned methods possess several disadvantages; for instance, it is required that the location of the damage be known a priori, the section of the structure under inspection needs to be easily accessible and in several cases, the structures must be closed temporarily during its inspection (Curadelli et al., 2008). These limitations have led to the development of new global monitoring methods. These methods are based on 
changes in the vibration characteristics on the structure, because vibration measurements are sensitive enough to detect damage, especially in the truss-type structures, where the vibration levels are high (Yan et al., 2012). The basic idea of vibration-based SHM is that modifications in structural characteristics affect the vibration response characteristics of structures (Talebinejad et al., 2011).

Several methods based on processing the structure vibration signals before and after damage have been proposed, which introduce certain features for the damage detection and its location by using a single technique. The most popular methods for structure condition monitoring are: Hilbert-Huang transform (HHT) (Mao and Que, 2006; Rezaei and Taheri, 2011; Razi et al., 2011), wavelet analysis (Han et al., 2005; Guo et al., 2005; Ren and Sun, 2008; Xiang and Liang, 2012), and multiple signal classification analysis (MUSIC) (Osornio-Rios et al., 2012). For example, Guo et al. (2005) investigated the use of wavelet packet transform (WPT) to extract features of vibration test data from a structure, where the wavelet energy rate index was the feature extracted and combined with an artificial neural network (ANN) to detect crack damage in a multi-story structure. The results showed that the proposed methodology was able to identify the damage; however, quantifying the damage presents small errors. Han et al. (2005) proposed a method based on the use of a WPT for the damage detection in beam structures, where the wavelet energy rate index was proposed and used to detect and locate the damage. The results were good; however, the methodology was tested using many sensors to locate a crack in a simple beam, which is costly, and the sensors were placed at the damage location, which is unrealistic in practical situations. Thus, the methodology needs to be tested in more complex structures. Ren and Sun (2008) used the combination of the wavelet transformation with Shannon entropy to detect and locate structural damage from measured vibration signals. The proposed method was experimentally tested in a beam structure and the experimental results showed the combination of methods helped to detect and locate crack damage in the structure. Similar to Han et al. (2005), Ren and Sun (2008) employed many sensors to locate a crack in a simple beam, and the sensors were placed at the damage location. Taha (2010) suggested the use of the discrete wavelet transform for detecting damage using the American Society of Civil Engineers (ASCE) benchmark structure. The wavelet energy rate index was proposed and used as an input of ANN to detect the damage. The results showed that it is possible to identify when an element is removed from a structure. Razi et al. (2011) proposed a novel vibration-based technique to detect and locate fatigue cracks in a beam. The method used the empirical mode decomposition (EMD) method to establish an energy-based damage index. The results showed that the proposed damage detection methodology can detect the presence and location of the damage. Unfortunately, the results are difficult to interpret and the sensors are placed next to damage; consequently, the proposed methodology might not work well if sensors are located far away of the damage. Xiang and Liang (2012) proposed a new methodology to detect and locate cracks in a beam by applying the wavelet transform to the modal shape. It was found that the proposed method works reasonably well at a certain level of noise. Recently, Osornio-Rios et al. (2012) presented a methodology for identifying, locating, and quantifying the severity of single damage. The fusion of two algorithms, MUSIC-ANN, for SHM applied to a five-bay truss-type structure is verified. The proposed methodology is effective for detecting a healthy structure, a structure with external corrosion and internal corrosion (IC), and a structure with a crack. However, in spite of the good results, the MUSIC algorithm has some limitations, as the algorithm is sensitive to the order, the technique consumes many computational resources, and it is not a general technique because the order selection is empirical. In addition, the aforementioned studies, although they employ a single technique to detect and locate damage, they present some difficulties that remain unresolved. These approaches are feasible only for monitoring the local damage of a single structural member or a simple structure, where the sensors are placed at the damage location. However, in a real structure, the sensors are randomly placed, and the proposed methodologies have only been tested under single damage. In real life, the structure can suffer two or more damage at the same time; therefore, it is necessary to find a methodology that provides a suitable, easy, and efficient way to locate and detect different single and 
combined damage in a more complex structure where the damage can be present simultaneously.

This paper presents a fused methodology of WPT and EMD, combined with ANN, for the identification and location of combined damage in a truss-type structure. The structure used in the case of study has five bays and was excited with an electrodynamic shaker. The proposed methodology is able to automatically locate and identify damage such as loosened bolts (LB), RS, IC, and their combinations in an automated monitoring process. A comprehensive experimental study to assess the utility of the proposed vibration-based SHM is presented. Results showed that the provided methodology can make a reliable assessment of the condition-location of the specific single or combined damage conditions. Moreover, the proposed methodology can be regarded as a simple, effective, and automated tool without the need for sophisticated analysis, to establish a practical, more general, and reliable SHM methodology.

\section{Structure}

\subsection{Truss-type structures}

Truss-type structures consist only of flexible truss members under axial forces, and are pinconnected at joints. The truss-type structure being tested consists of a five-bay structure made of aluminum, which is recessed in a concrete wall. Each assembled bay is a $0.7071 \mathrm{~m}$ cube-shaped structure. Bar elements are made of aluminum and those elements located in the $X, Y$, and $Z$ directions have dimensions of $0.7071 \mathrm{~m} \times 0.019 \mathrm{~m}$ of length and diameter, respectively. The dimensions for diagonal members are $1 \mathrm{~m} \times 0.019 \mathrm{~m}$ of length and diameter, respectively. The connection node has a mass of $0.2 \mathrm{~kg}, 0.055 \mathrm{~m}$ side and is bolt connected with the bar elements. Fig. 1a shows the complete geometric configuration of the structure under test. Fig. 1b shows an assembly of a bar element used in the fabricated structure which consists of a bar with bolt connected nodes.

A finite element model (FEM) was performed to locate the natural frequencies of the structure under study. In the region from $15 \mathrm{~Hz}$ to $150 \mathrm{~Hz}$ the first

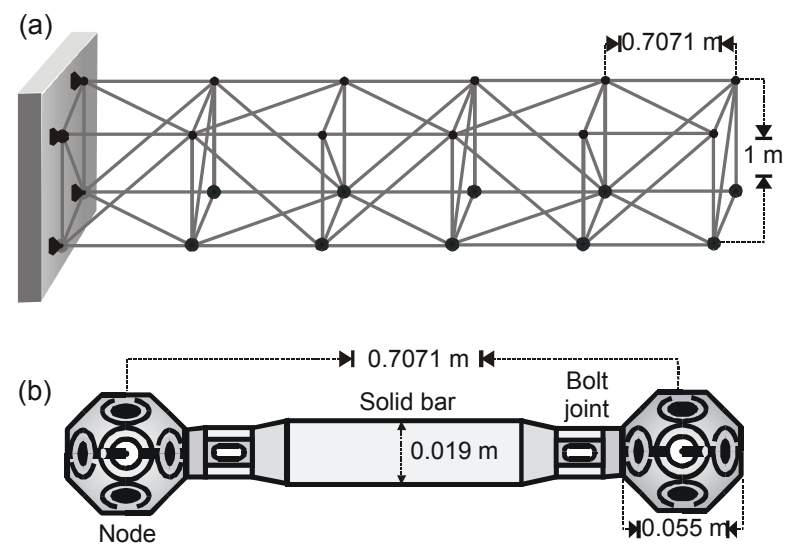

Fig. 1 Truss-type structure (a) and typical assembly of a bar element (b)

natural frequencies were found; therefore, this region was selected to excite the structure; since it is susceptible to changes because of damage. The damage under study was experimentally analyzed.

\subsection{Damage under study}

In order to validate the proposed methodology, various types of damage including $\mathrm{LB}, \mathrm{RS}, \mathrm{IC}$, and their combinations are proposed in this work.

\subsubsection{Loosened bolt (LB)}

LB is a frequent damage in truss-type structures. This damage occurs due to vibrations caused by strong winds, traffic, etc. It is then common to discover that recently installed bolts in the structure are loosened (Yan et al., 2012). To carry out the LB test, one side of the bar element is separated from the bolt connector as shown in Fig. 2 a.

\subsubsection{Reduced stiffness (RS)}

Another kind of damage regularly present in truss-type structures is the RS of their elements, which can be produced by corrosion, changes in temperature, etc., and produces a local decrease of the cross-sectional area of the affected element (Chen et al., 2005; Osornio-Rios et al., 2012). To simulate the RS condition, a bar element with a reduced diameter $(0.013 \mathrm{~m})$ is used; therefore, the bar element stiffness has been reduced by $53 \%$. Fig. $2 \mathrm{~b}$ illustrates the comparison between the healthy bar element and the damaged bar element with the reduced diameter. 
(a)

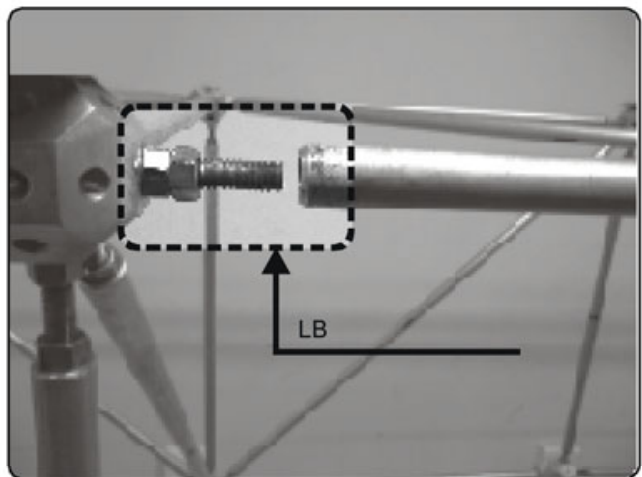

(b)

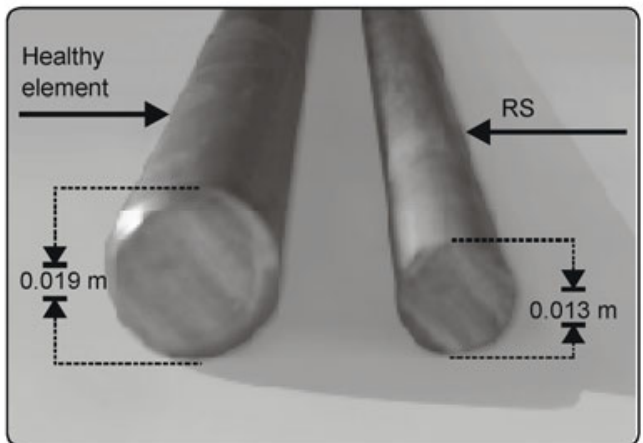

(c)

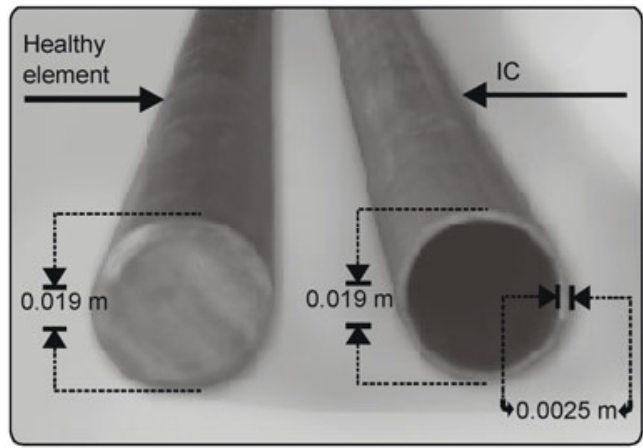

Fig. 2 Damage under study: LB (a), RS (b), and IC (c)

\subsubsection{Internal corrosion (IC)}

Corrosion is one of the most serious forms of damage in structural performance. Truss-type structures are mainly made of tube elements, which can often suffer IC because of water filtrations, humidity, etc. (Chen et al., 2005). To simulate the IC test, a tube element is used instead of a solid bar. The dimensions of the tube elements are $0.019 \mathrm{~m}$ for the exterior diameter and $0.0165 \mathrm{~mm}$ for the interior diameter. Fig. $2 \mathrm{c}$ shows the comparison between the healthy bar element and the damaged tube element. A tube element is used to simulate the IC; nevertheless, it is necessary to consider that the solid bar is perforated with a drill of $9.5 \mathrm{~mm}$ in order to connect it with the node; therefore, the reduction of material to simulate the IC is $7 \mathrm{~mm}$.

\subsubsection{Combined damage}

The multiple-combined damage conditions applied to the structure are obtained by combining each single damage condition with one or two of the remaining damage conditions. Fig. 3 depicts the different arrangements for the multiple-combined damage conditions, where there are seven possible cases.

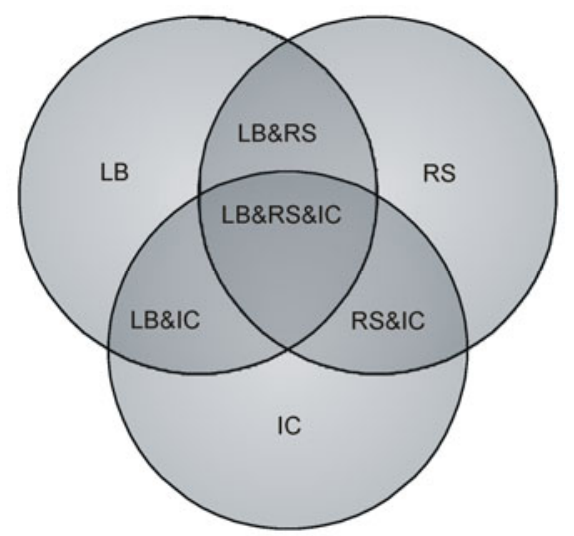

Fig. 3 Combinations for the analysis of the single and multiple-combined damages

\section{Theoretical background}

\subsection{Wavelet packet transform (WPT)}

WPT, like discrete wavelet transform (DWT), is a technique that decomposes a signal repeatedly into successive low- and high-frequency components. Even so, in WPT, the approximation and detail coefficients are decomposed to create the full binary tree of band decomposition. Therefore, WPT can provide uniform frequency bands, different from DWT where just the approximation coefficients are decomposed (Amezquita-Sanchez et al., 2012). WPT is defined by Eq. (1), where $j$ and $k$ are integer numbers that represent the scale and translation, respectively, and $n$ represents the modulation or oscillation parameter.

$$
W_{j, k}^{n}(t)=2^{j / 2} W^{n}\left(2^{j} t-k\right)
$$

WPT is obtained through the next recursive Eqs. (2) and (3), where $t$ is the time variable, $h(k)$ is the low-pass filter coefficients, and $g(k)$ and $W^{n}$ are 
the high-pass filter coefficients associated with the scaling function and the mother wavelet, respectively.

$$
\begin{aligned}
W^{2 n}(t) & =\sqrt{2} \sum_{k=-\infty}^{\infty} h(k) W^{n}(2 t-k), \\
W^{2 n+1}(t) & =\sqrt{2} \sum_{k=-\infty}^{\infty} g(k) W^{n}(2 t-k) .
\end{aligned}
$$

The wavelet packet component energy is defined by

$$
E_{f j}^{n}(\mathrm{WPT})=\int_{-\infty}^{\infty} f_{j}^{n}(t)^{2} \mathrm{~d} t,
$$

where $f_{j}^{n}$ is the $n$th level signal component decomposed at the $j$ th level by the wavelet function and translated in the time domain.

The coefficients for each wavelet node $h(j, k)$ and $g(j, k)$ can be obtained through the inner products of $x(t)$ with the corresponding wavelets as shown in Eq. (5). The signal reconstruction is done by applying the process in an inverse way, which is known as the inverse WPT (IWPT). Fig. 4 displays the decomposition and reconstruction process of the wavelet packet. According to Fig. 4, the frequency bands for each node of a 1-level decomposition, $h(1,0)$ and $g(1,1)$, with a sampling frequency $F_{\mathrm{s}}=320 \mathrm{~Hz}$ are $0-80 \mathrm{~Hz}$ and $80-160 \mathrm{~Hz}$, respectively.

$$
S_{j, k}=\int_{\mathbb{R}} x(t) W_{j, k}^{n}(t) \mathrm{d}(t) .
$$

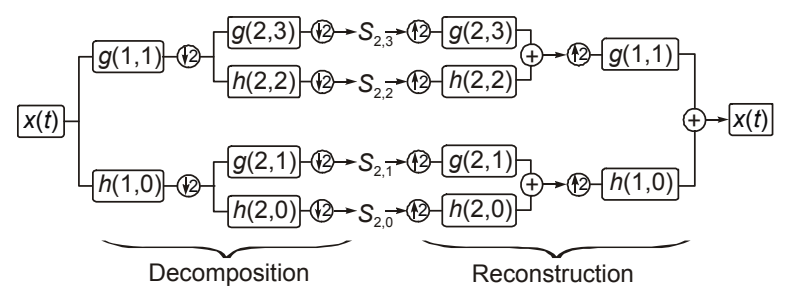

Fig. 4 Wavelet packet decomposition and reconstruction

\subsection{Empirical mode decomposition (EMD)}

The EMD method is better suited to dealing with data from nonstationary and nonlinear processes. The EMD method decomposes a signal into oscillating components obeying some basic properties, namely intrinsic mode functions (IMFs). The principle of EMD is to decompose any signal $s(t)$ into a set of band-limited functions $C_{n}(t)$, which are zero mean oscillating components, called IMF. Each IMF satisfies two basic conditions: (1) in the whole data set, the number of extrema and the number of zero crossings must either be equal to or varied by at most one; (2) at any point, the mean value of the envelope defined by the local maxima and the envelope defined by the local minima is zero (Huang et al., 1998).

The name IMF is adopted because it represents the oscillation mode in the signal. Thus, the IMF in each cycle is defined by the zero crossings and involves only one mode of oscillation, where no complex riding waves are allowed. The idea of finding the IMF relies on subtracting the highest oscillating components from the signal with a step-by-step process, the sifting process:

1. Identify the maxima and minima of $s(t)$.

2. Generate the upper and lower envelopes $(u(t)$ and $l(t)$ respectively) by cubic spline interpolation.

3. Determine the local mean $m_{1}(t)=[u(t)+l(t)] / 2$.

4. Since IMF should have zero local mean, subtract $m_{1}(t)$ from $s(t)$ to obtain $h_{1}(t)$.

5. Check whether $h_{1}(t)$ is an IMF or not.

6. If not, use $h_{1}(t)$ as the new data and repeat steps 1 to 5 until ending up with an IMF.

Once the first IMF $h_{1}(t)$ is obtained, it is defined as $C_{1}(t)=h_{1}(t)$, which is the smallest temporal scale in the signal $s(t)$. To compute the remaining IMF, $C_{1}(t)$ is subtracted from the original signal to get the residue signal $r_{1}(t): r_{1}(t)=s(t)-C_{1}(t)$. The residue now contains information about the components of longer periods. The sifting process will be continued until the final residue is a constant, a monotonic function, or a function with only one maxima and one minima from which no more IMF can be obtained (Rezaei and Taheri, 2009). The subsequent IMF and the residues are computed as

$$
\begin{aligned}
& r_{1}(t)-C_{2}(t) \\
& \quad=r_{2}(t)-C_{3}(t), r_{3}(t)-C_{4}(t), \ldots, r_{n-1}(t)-C_{n}(t) \\
& =r_{n}(t) .
\end{aligned}
$$

At the decomposition end, the signal $s(t)$ will be represented as a sum of $n$ IMF signals plus a residue signal: 


$$
s(t)=\sum_{i=1}^{n} C_{i}(t)+r_{n}(t) .
$$

The energy of the desired IMF can be established by

$$
E(\mathrm{IMF})=\int_{0}^{t_{0}}(\mathrm{IMF})^{2} \mathrm{~d} t
$$

where $t_{0}$ is defined as the signal duration.

\subsection{Artificial neural network (ANN)}

ANN is a pursuit of simulating the interconnected neurological structure of the human brain, which has been proven to be suitable of learning and solving problems through pattern recognition. Several ANN architectures have been used in civil engineering applications (Adeli, 2001); however, the multilayered perceptron (MLP) architecture is the most commonly used ANN. The MLP architecture consists of an input layer, one or more hidden layers, and an output layer, where each layer is composed of a variable number of nodes (Fig. 5).

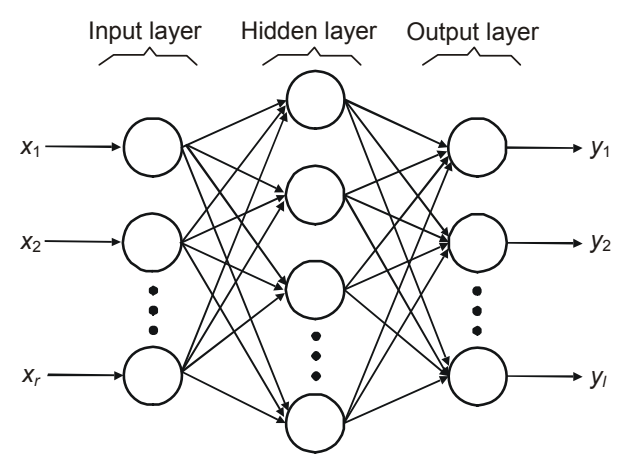

Fig. 5 MLP architecture for an ANN

The $r$ nodes in the input layer distribute the information to the nodes in the hidden layer, which performs a nonlinear transformation on the weighted sum of the inputs; afterwards, the results are passed to the $l$ nodes in the output layer. The back-propagation algorithm or algorithm of inverse propagation is the most used training method in the previous studies of MLP network. This algorithm consists of mapping the input process to the desired outputs by minimizing the error between the desired outputs and the calculated outputs (Huang, 2009).
In this study, an MLP network architecture is carried out for identification-location of single and multiple-combined structural damage. The proposed ANN consists of five input nodes, which receive values from the IMF block, obtained by information energy of the vibration signal acquired by each sensor (five sensors placed in each one of the five bays in the structure), with 90 nodes in the first hidden layer and 50 nodes in the second hidden layer to provide the best results in the proposed methodology. The nine output nodes are the flags indicating the structure condition healthy structure, LB, RS, and IC, and the locations of damage condition, first-bay, second-bay, and so on up to the fifth-bay. In the first four outputs, each node agrees to a single-damage condition; and if two or more damage are present at the same time, the corresponding output nodes will be triggered up. The nodes at the hidden and output layers have a log-sigmoid (LS) activation function, which is defined by Eq. (9), where $\beta$ is the sum of the inputs to the nodes. The proposed ANN is implemented in the Matlab digital signal processing toolbox, which is trained using a back-propagation algorithm.

$$
\operatorname{LS}(\beta)=\frac{1}{1+\mathrm{e}^{-\beta}}
$$

\section{Methodology}

Vibration signature analysis is employed to determine the state of a structure. It can be used to establish a damage feature index, which allows for monitoring of the structure condition in order to detect the presence of damage. A structural damage produces changes in the vibration response of the structure by inducing variations in its energy. Therefore, the vibration analysis is a powerful diagnostic and troubleshooting tool of structure health monitoring. The proposed methodology for identificationlocation of damage diagnosis by vibration signature analysis through integration of the information energy and ANN algorithms includes the following steps:

1. Acquire vibration data from the five sensors placed in each bay of a healthy five-bay truss-type structure (without damage), which is taken as the baseline.

2. Decompose the acquired signal into different 
frequency bands (nodes) by applying the WPT method. At the same time, decompose the acquired signal into distinctive IMF by applying the EMD method.

3. Select the frequency band (node) and the IMF that provide information about the natural frequencies of the structure. In this work, the node $(1,0)$ selected corresponded to the frequency range $(0-80 \mathrm{~Hz})$. In addition, the Daubechies (db4) is used as the mother wavelet because it is the best suited for the proposed methodology (Wang et al., 2008). The selected node was experimentally determined; in this node it was found that the energy is more sensitive to the damage. As well, the first IMF was selected because it contains most of the natural frequencies, and the energy calculation is more stable than the other IMF (e.g., IMF2, IMF3, ...); therefore, the repeatability of the calculated energies is possible. To extend this point to other structures, it is necessary to identify a bandwidth or region, which contains most of the natural frequencies of the structure, with the aim of having more energy. For example, when the structure is healthy (sensor-1), the energy of node $(1,0)$ and the first IMF are 0.5700 and 0.6413 , respectively. On the other hand, the energy of node $(1,1)$ and the second IMF are 0.2423 and 0.0186 , respectively. Therefore, the node $(1,0)$ and the first IMF contain the most energy of the system.

4. Estimate the energy contents in the node (WPT) and the selected IMF.

5. Sequential damage in each bay is induced independently; this means the damage in the first bay is repaired before advancing to the second-bay and so on. From here, damage is applied to the first-bay, and data are acquired from the sensors in a similar way to step 1.

6. Then the node and IMF are obtained as in steps 2 and 3 to establish the analysis region of the damaged condition.

7. Steps $2-5$ are repeated for all the bays in the structure, and their respective energies are obtained.

8. The damage feature index is obtained from the computed energies fusion, and it is an indicative of structure-condition. The damage index computing method is further described later in this section.

9. The obtained damage feature index is used to train the ANN algorithm, in order to diagnose the health-condition within the truss-type structure.

\subsection{Damage feature index}

For a given structural damage, the data acquired from several sensors fixed at different locations in the structure contain distinctive information. Thus, each sensor has distinct sensitivity to the structural damage, which is transferred to the energy computed in the vibration signal. In this work, a new damage feature index based on fusion of the energies obtained by a single wavelet-packet node and the first intrinsic mode function $\left(\mathrm{IMF}_{1}\right)$ in the vibration signal from each of the five sensors is proposed.

The proposed damage index computing for the identification-location of different damages and their combination applied to a truss-type structure through the analysis of a single parameter is described by

$$
\mathrm{DIV}=E(\mathrm{IMF})+E(\mathrm{WPT}),
$$

where DIV, $E(\mathrm{IMF})$, and $E(\mathrm{WPT})$ are the damage index value, energy of IMF, and energy of WPT, respectively. Once calculated, DIV for each sensor, the obtained damage feature indexes are used to train the ANN algorithm; where the existence and location of damage are identified in the structure. The damage index value is a scalar value, which will increase if there is damage in the structure. However, the proposed index has not yet been fully studied and requires more study to observe the effects of the local damage in the vibration level of a structure.

In order to monitor the condition of other structure the proposed damage index should be represented in percentage only, which allows locating the damage in an automatic fashion. This percentage is the difference in the structure's energy at its healthy and damaged states, which is described by

$$
\begin{aligned}
\mathrm{DIV}= & \left(\left|\frac{E(\mathrm{IMF})_{\text {Healthy }}-E(\mathrm{IMF})_{\text {Damaged }}}{E(\mathrm{IMF})_{\text {Healthy }}}\right|\right. \\
& \left.+\left|\frac{E(\mathrm{WPT})_{\text {Heathy }}-E(\mathrm{WPT})_{\text {Damaged }}}{E(\mathrm{WPT})_{\text {Healthy }}}\right|\right) \times 100 .
\end{aligned}
$$

Once DIV is calculated for each sensor, the relatively high index values are identified as indicators for the existence of damage close to the respected sensor, thereby the existence and location of damage are identified accordingly. 


\subsection{Network training}

The ANN was trained through a backpropagation algorithm for identification-location of different single and combined damage in a truss-type structure. Ten trials were carried out under each damage condition. The training set for each damage condition was synthetically obtained by randomly producing 250 damage index values within the range $[\mu-3 \sigma, \mu+3 \sigma]$, where $\mu$ is the mean, and $\sigma$ is the standard deviation of the calculated damage index values from the ten trials. Real values were used as a validation set for the corresponding damage condition and its localization. Fig. 6 depicts the estimated damage index value-1 from sensor-1 $\left(\mathrm{DIV}_{1}\right)$ as Gaussian functions for the three damage conditions and their combinations respectively, which were obtained from 10 trials for each structure condition. The obtained DIV $_{1}$ shows that each damage condition has different sensitivity due to the kind of damage and its location. Furthermore, it is possible to observe that some areas overlap, for instance, in LB, locating damage in the second-bay with the damage in the third-bay. However, the damage index value corresponds to the sensor- 1 and there are four other damage index values that are applied to the ANN as explained in the next section. Thus, this proves that it is important to have information from several sensors because of those containing different information from damage. Table 1 lists the behavior of the first IMF energy and WPT energy according to local damage and their combinations. This table shows the average of 10 tests for each condition. It is possible to observe that the energy varies according to the damage and its location; besides, the energy variation with single damage is little, in comparison, to the combined damage, which is large. Moreover, Table 1 shows that the energy variation is not monotonous with the local damage. Additionally, it is important to clarify that the calculated energies are not global parameters and they change according to the signal vibration.
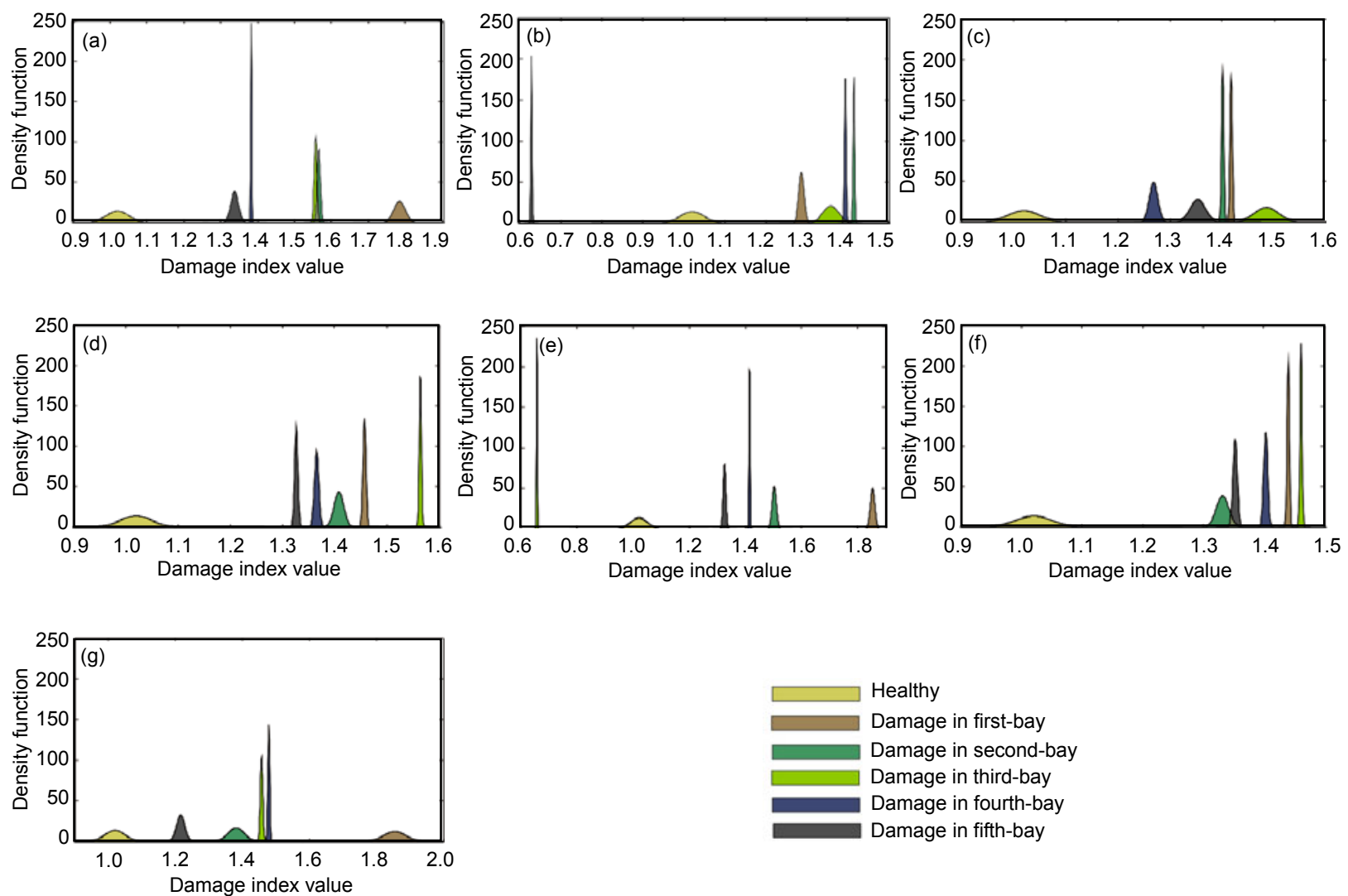

Fig. 6 Density functions defining detectability zones obtained by proposed damage index values from sensor-1 for LB (a), RS (b), IC (c), LB\&RS (d), LB\&IC (e), RS\&IC (f), and LB\&RS\&IC (g) 
Table 1 Behaviors of IMF-energy and WPT-energy

\begin{tabular}{|c|c|c|c|c|c|c|c|c|c|c|c|}
\hline \multirow{2}{*}{$\begin{array}{l}\text { Structure } \\
\text { condition }\end{array}$} & \multirow{2}{*}{ Sensor } & \multicolumn{5}{|c|}{ IMF } & \multicolumn{5}{|c|}{ WPT } \\
\hline & & 1st-bay & 2nd-bay & 3rd-bay & 4th-bay & 5th-bay & 1st-bay & 2nd-bay & 3rd-bay & 4th-bay & 5th-bay \\
\hline \multirow{5}{*}{ LB } & 1 & 0.760 & 0.520 & 0.489 & 0.509 & 0.438 & 1.012 & 0.622 & 0.629 & 0.623 & 0.588 \\
\hline & 2 & 0.396 & 0.422 & 0.362 & 0.304 & 0.281 & 0.859 & 0.902 & 0.857 & 0.783 & 0.761 \\
\hline & 3 & 0.261 & 0.239 & 0.291 & 0.197 & 0.313 & 0.795 & 0.758 & 0.841 & 0.638 & 0.866 \\
\hline & 4 & 0.134 & 0.157 & 0.132 & 0.252 & 0.254 & 0.726 & 0.703 & 0.709 & 0.776 & 0.784 \\
\hline & 5 & 0.053 & 0.078 & 0.076 & 0.050 & 0.055 & 0.616 & 0.601 & 0.631 & 0.611 & 0.798 \\
\hline \multirow{5}{*}{ RS } & 1 & 0.512 & 0.528 & 0.546 & 0.528 & 0.494 & 0.825 & 0.858 & 0.753 & 0.765 & 0.134 \\
\hline & 2 & 0.403 & 0.428 & 0.391 & 0.404 & 0.332 & 0.826 & 0.881 & 0.719 & 0.772 & 0.292 \\
\hline & 3 & 0.270 & 0.240 & 0.203 & 0.238 & 0.270 & 0.795 & 0.774 & 0.756 & 0.782 & 0.813 \\
\hline & 4 & 0.184 & 0.158 & 0.157 & 0.192 & 0.239 & 0.672 & 0.727 & 0.720 & 0.862 & 0.764 \\
\hline & 5 & 0.089 & 0.085 & 0.079 & 0.072 & 0.045 & 0.626 & 0.617 & 0.595 & 0.627 & 0.850 \\
\hline \multirow{5}{*}{ IC } & 1 & 0.555 & 0.539 & 0.587 & 0.470 & 0.494 & 0.861 & 0.860 & 0.815 & 0.793 & 0.852 \\
\hline & 2 & 0.426 & 0.439 & 0.444 & 0.404 & 0.391 & 0.773 & 0.873 & 0.718 & 0.878 & 0.864 \\
\hline & 3 & 0.255 & 0.240 & 0.295 & 0.290 & 0.242 & 0.779 & 0.768 & 0.839 & 0.831 & 0.796 \\
\hline & 4 & 0.174 & 0.173 & 0.188 & 0.212 & 0.218 & 0.739 & 0.738 & 0.769 & 0.785 & 0.781 \\
\hline & 5 & 0.080 & 0.077 & 0.090 & 0.084 & 0.147 & 0.617 & 0.607 & 0.639 & 0.634 & 0.666 \\
\hline \multirow{5}{*}{ LB\&RS } & 1 & 0.577 & 0.528 & 0.625 & 0.533 & 0.500 & 0.882 & 0.876 & 0.839 & 0.856 & 0828 \\
\hline & 2 & 0.396 & 0.429 & 0.437 & 0.347 & 0.320 & 0.844 & 0.902 & 0.810 & 0.836 & 0.817 \\
\hline & 3 & 0.287 & 0.213 & 0.307 & 0.399 & 0.284 & 0.810 & 0.773 & 0.839 & 0.947 & 0.865 \\
\hline & 4 & 0.194 & 0.131 & 0.172 & 0.346 & 0.280 & 0.776 & 0.730 & 0.743 & 0.855 & 0.835 \\
\hline & 5 & 0.093 & 0.073 & 0.085 & 0.042 & 0.045 & 0.641 & 0.630 & 0.629 & 0.611 & 0.912 \\
\hline \multirow{5}{*}{ LB\&IC } & 1 & 0.809 & 0.590 & 0.432 & 0.558 & 0.496 & 1.049 & 0.908 & 0.241 & 0.856 & 0.829 \\
\hline & 2 & 0.430 & 0.477 & 0.369 & 0.344 & 0.316 & 0.897 & 0.922 & 0.366 & 0.825 & 0.802 \\
\hline & 3 & 0.238 & 0.244 & 0.322 & 0.386 & 0.264 & 0.804 & 0.779 & 0.870 & 0.926 & 0.846 \\
\hline & 4 & 0.134 & 0.155 & 0.127 & 0.308 & 0.248 & 0.740 & 0.731 & 0.523 & 0.818 & 0.812 \\
\hline & 5 & 0.070 & 0.080 & 0.072 & 0.040 & 0.036 & 0.634 & 0.622 & 0.410 & 0.608 & 0.859 \\
\hline \multirow{5}{*}{ IC\&RS } & 1 & 0.528 & 0.527 & 0.563 & 0.527 & 0.504 & 0.842 & 0.8696 & 0.899 & 0.829 & 0.849 \\
\hline & 2 & 0.372 & 0.458 & 0.404 & 0.376 & 0.335 & 0.839 & 0.8875 & 0.869 & 0.521 & 0.825 \\
\hline & 3 & 0.267 & 0.244 & 0.249 & 0.244 & 0.261 & 0.783 & 0.766 & 0.987 & 0.924 & 0.814 \\
\hline & 4 & 0.210 & 0.144 & 0.222 & 0.144 & 0.272 & 0.758 & 0.712 & 0.806 & 0.403 & 0.841 \\
\hline & 5 & 0.089 & 0.077 & 0.065 & 0.077 & 0.187 & 0.622 & 0.613 & 0.620 & 0.411 & 0.723 \\
\hline \multirow{5}{*}{$\begin{array}{c}\text { LB\&RS } \\
\& I C\end{array}$} & 1 & 0.823 & 0.644 & 0.553 & 0.568 & 0.437 & 1.013 & 0.922 & 0.907 & 0.893 & 0.787 \\
\hline & 2 & 0.457 & 0.471 & 0.327 & 0.426 & 0.312 & 0.895 & 0.934 & 0.839 & 0.914 & 0.789 \\
\hline & 3 & 0.339 & 0.283 & 0.330 & 0.346 & 0.251 & 0.819 & 0.800 & 0.865 & 0.870 & 0.791 \\
\hline & 4 & 0.185 & 0.168 & 0.146 & 0.297 & 0.206 & 0.746 & 0.737 & 0.720 & 0.813 & 0.754 \\
\hline & 5 & 0.104 & 0.106 & 0.075 & 0.078 & 0.177 & 0.623 & 0.626 & 0.625 & 0.616 & 0.663 \\
\hline \multirow{5}{*}{ Healthy } & 1 & & & 0.570 & & & & & 0.641 & & \\
\hline & 2 & & & 0.388 & & & & & 0.646 & & \\
\hline & 3 & & & 0.259 & & & & & 0.652 & & \\
\hline & 4 & & & 0.175 & & & & & 0.645 & & \\
\hline & 5 & & & 0.091 & & & & & 0.576 & & \\
\hline
\end{tabular}

On the other hand, Fig. 7 shows the estimated index values according to Eq. (12). Figs. 7a-7c display the obtained index values for detect and locate
LB, LB\&RS, and LB\&RS\&IC. It is possible to observe that the relatively high index values are identified as indicators for the existence of damage and its 
location close to the respected sensor, which can be employed to train the ANN in order to identify the damage and monitor the structure. Figs. $7 \mathrm{~d}$ and $7 \mathrm{e}$ show the percentage using IMF-energy, and Figs. $7 \mathrm{f}-$ $7 \mathrm{~h}$ present the percentages by WPT-energy. Figs. $7 \mathrm{~d}-7 \mathrm{~h}$ demonstrate that using the energy of a single technique is difficult to detect and locate the damage, since in several cases the sensor with larger energy is located far away from damage location; therefore, the fusion of energies to detect and locate the damage according to the location of sensors is necessary.

\subsection{Energy neural process}

Fig. 8 depicts the flow of the applied process for detection-location of different damage conditions, and their possible combinations on a truss-type structure. The energy neural process consists of three main units: the WPT and IMF algorithms for isolating the analysis region, and the energy calculation.

Both analyses are used to find out the damage index values $\left(\mathrm{DIV}_{1}, \mathrm{DIV}_{2}, \mathrm{DIV}_{3}, \mathrm{DIV}_{4}\right.$, and $\left.\mathrm{DIV}_{5}\right)$, which are obtained fusing both energies, and the ANN algorithm is used to identify the condition and location of the damage in the truss-type structure from the estimated damage index values.

\section{Experiments}

The experimental setup is shown in Fig. 9, where the location of each accelerometer used for monitoring the behavior of a reconfigurable five-bay space
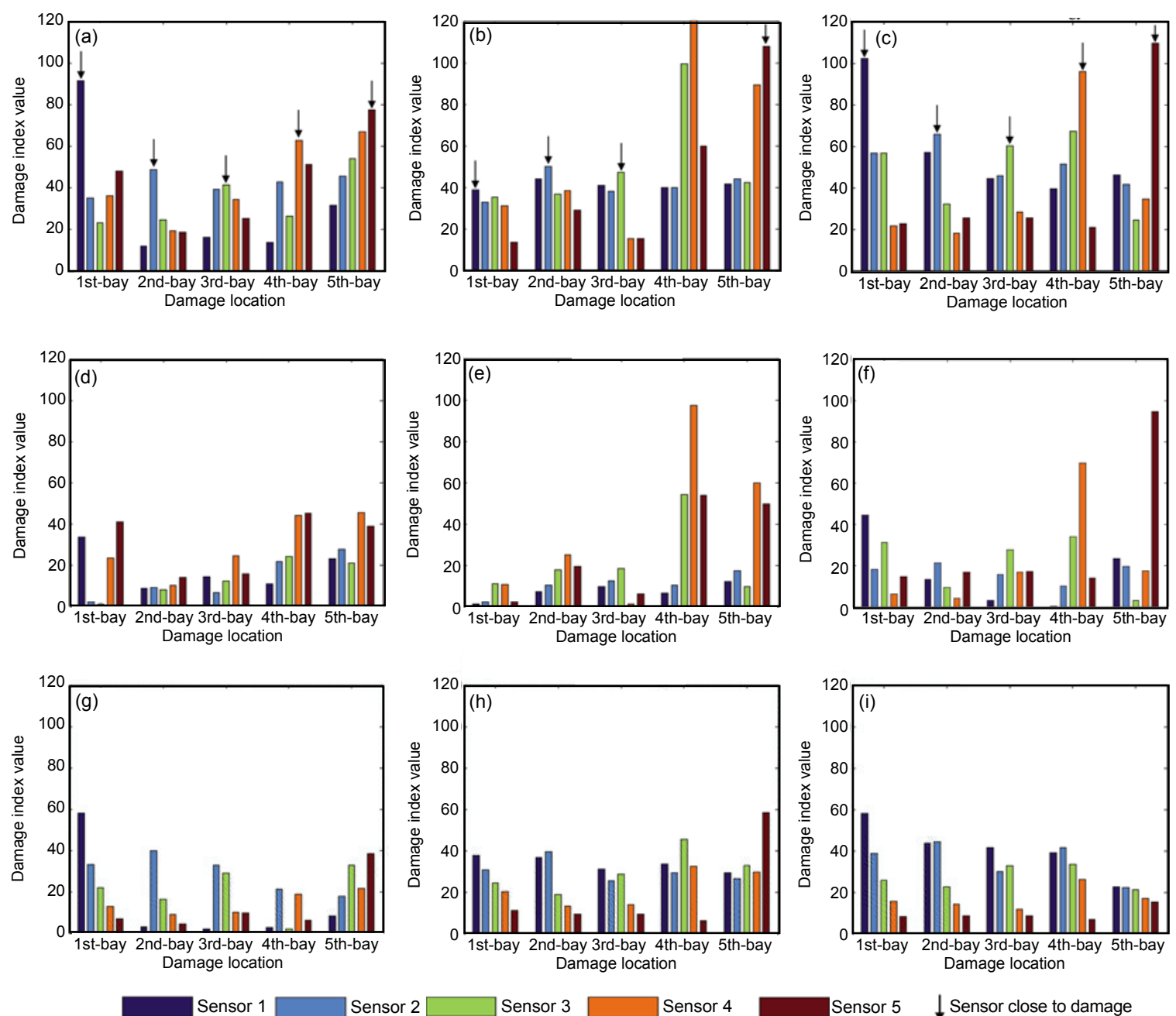

Fig. 7 Behaviors of IMF-energy and WPT-energy in percentages

(a) LB: IMF-energy+WPT-energy; (b) LB\&RS: IMF-energy+WPT-energy; (c) LB\&RS\&IC: IMF-energy+WPT-energy; (d) LB: IMF-energy; (e) LB\&RS: IMF-energy; (f) LB\&RS\&IC: IMF-energy; (g) LB: WPT-energy; (h) LB\&RS: WPT-energy; (i) LB\&RS\&IC: WPT-energy 
truss-type structure made of aluminum is exhibited (Fig. 9a). The vibration signal is acquired using a micro-elecromechanical system (MEMS)-based tri-axial accelerometer model LIS3L02 AS4 from STMicroelectronics. The accelerometer has a userselectable full-scale of $\pm 2 g / \pm 6 g\left(g=9.81 \mathrm{~m} / \mathrm{s}^{2}\right)$, a 0.66 $\mathrm{V} / \mathrm{g}$ sensitivity, a bandwidth of $750 \mathrm{~Hz}$, and a $5 \times 10^{-4} \mathrm{~g}$ resolution over a $100 \mathrm{~Hz}$ bandwidth (Fig. 9c). The obtained signals from the sensor network are stored in a proprietary data-acquisition system (DAS) and are sent to PC by USB protocol (Fig. 9d). The sampling frequency of the DAS is set to $3.2 \mathrm{kHz}$, obtaining 48 000 samples during a period of $15 \mathrm{~s}$. To perform the modal testing, an electrodynamic shaker from Labworks model ET-127 powered by a linear power amplifier from Labworks Model PA-141 (LabWorks Inc., USA) is used as the excitation source (Fig. 9b). Simultaneously, the amplifier is fed by a proprietary digital waveform synthesizer (Fig. 9d).

In order to reduce the computation time and to optimize the damage index value estimation, the acquired signal is decimated to limit the useful frequency region, leading to a lower signal-toquantization noise ratio (SQNR) (Tan and Wang, 2011). The acquired vibration signal is decimated 10 times to limit the sampling frequency to $320 \mathrm{~Hz}$ and the frequency range from 0 to $160 \mathrm{~Hz}$, because the region of interest lies below $150 \mathrm{~Hz}$. The proposed experiments use a sinusoidal sweep with a frequency range from 15 to $150 \mathrm{~Hz}$ over a period of $15 \mathrm{~s}$ to excite

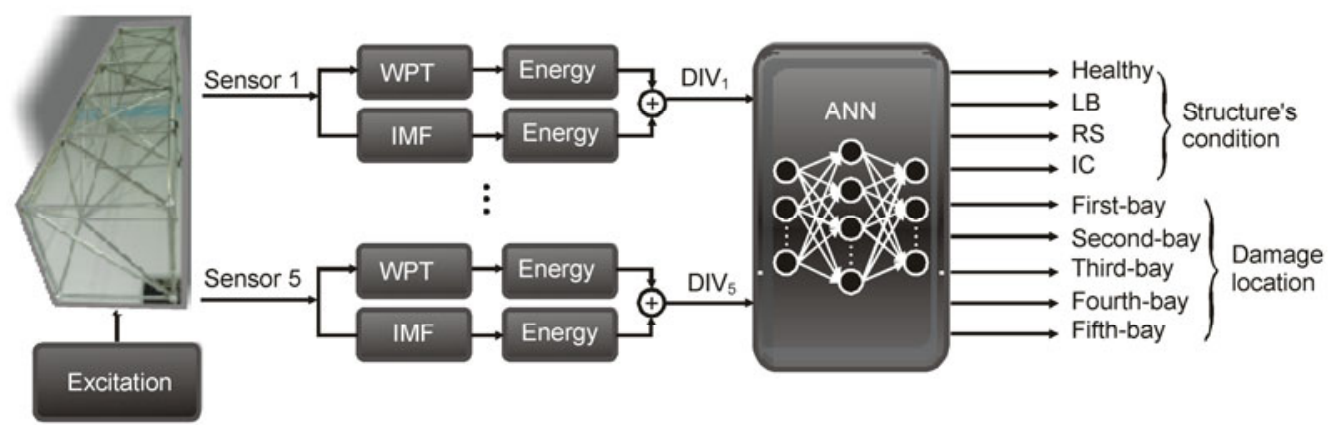

Fig. 8 Energy neural process
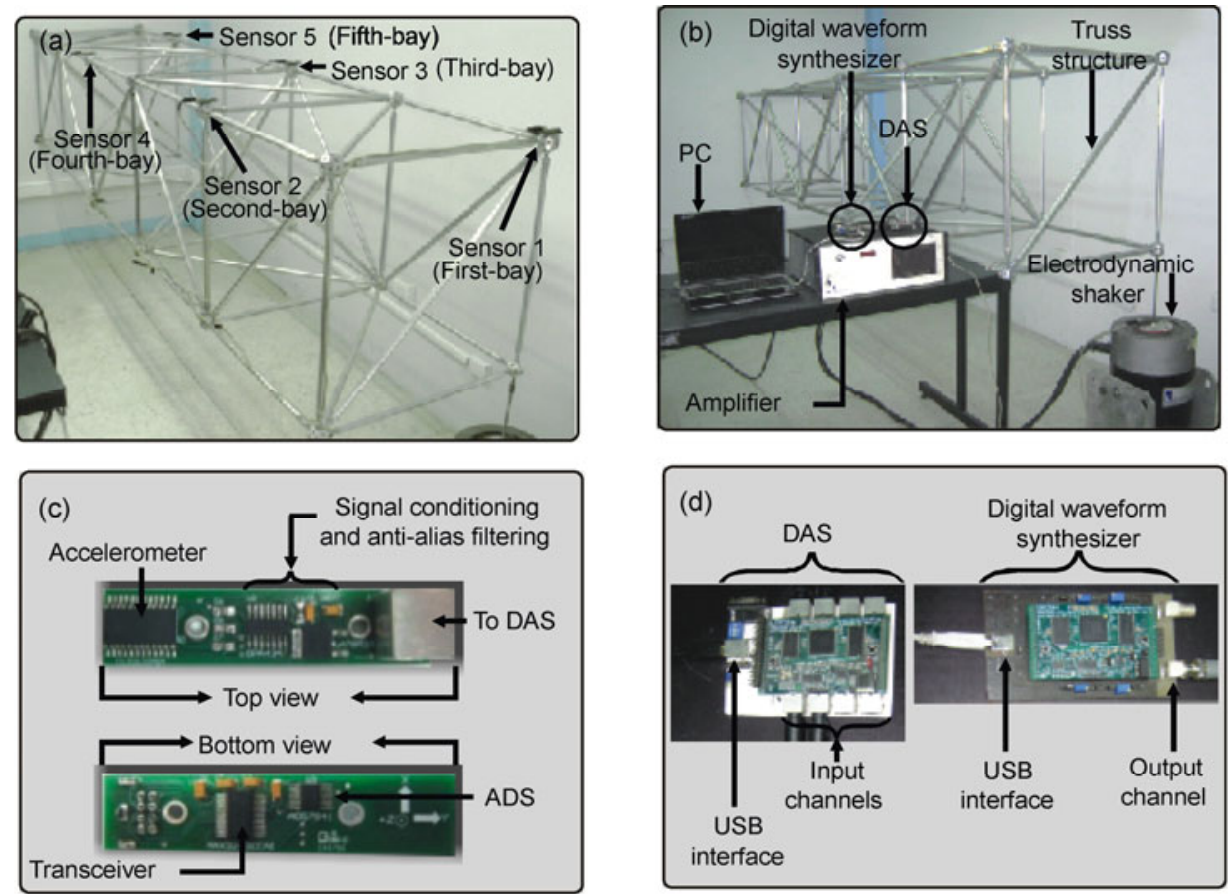

Fig. 9 Experimental setup

(a) Structure under test; (b) Overall system; (c) Tri-axial accelerometer; (d) Digital waveform synthesizer and data acquisition system 
the structure. Fig. 10 displays the locations of different single and multiply-combined damages, applied to the truss-type structure, where sequential damage in each bay is induced independently.

This means that the damage in the first bay is repaired before advancing to the second-bay and so on. The circle, black line, and the dotted line indicate the location of LB, RS and IC damage respectively. For example, Fig. 10d shows a close-up of the second-bay, where it is possible to observe the location of a single damage and IC; it is important to mention that in the same location there are two other damage, which are applied one at a time in the structure. Fig. 10a presents the location of the single damage in the other four bays. On the other hand, Fig. 10e displays a close-up of the third-bay, where two points of damage are applied at the same time, RS and IC. In addition, Fig. 10b presents the locations of the other two combinations of damage (LB\&IC, LB\&RS) in the other four bays. Fig. 10f displays an example of location of three combined damage in the first-bay, and Fig. 10c shows the location of three combined damage in the other four bays.

\section{Results and discussion}

Table 2 presents the obtained results by the proposed methodology (IMF-WPT-ANN) and the results obtained with the other three methodologies proposed in previous studies, i.e., IMF-energy (Razi et al., 2011), WPT-energy (Han et al., 2005), and MUSIC-ANN (Osornio-Rios et al., 2012), which were applied to the five-bay truss-type structure for identification, and locations of single and multiplecombined damage. This table shows that fusing the IMF and WPT methodologies with the ANN method, increases the effectiveness of carrying out the truss-structure condition monitoring, where the single methodologies were not able to do it.

According to the seven plots of density functions vs. damage index values as shown in Fig. 6, it is possible to observe that only three plots (LB, RS, and RS\&IC), show overlap locations. However, the plots from Fig. 6 correspond to the energy analysis from sensor- 1 only, and the proposed methodology is also applied to the four other sensors. Results from the energy analysis of all five sensors are the input nodes of the ANN, which contains 90 and 50 nodes in the hidden layer, and 9 output nodes to assert the diagnosis. From the output nodes of the ANN, it is possible to obtain a $100 \%$ certainty for all studied cases; the correct decision for identification and location of the multiple-combined damage applied to a truss-type structure can be seen in Table 2. The results included identifying a healthy condition and a single isolated fault, combining two or three damage conditions, as well as locating the damage in one of the five bays. For all these cases, 10 tests were performed to acquire the vibration signals from the truss-type structure excited by an electrodynamic shaker.

Results showed that the proposed methodology has $100 \%$ effectiveness for detecting health conditions in a five-bay truss-type structure. The proposed methodology can detect and distinguish three different kinds of single damage such as LB, RS, IC, and (a)

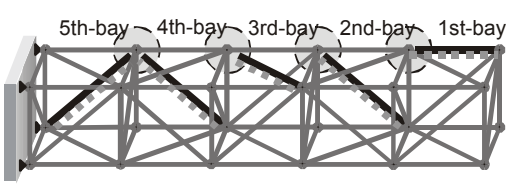

(d)

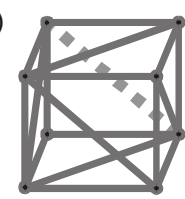

Cocation of LB (b)

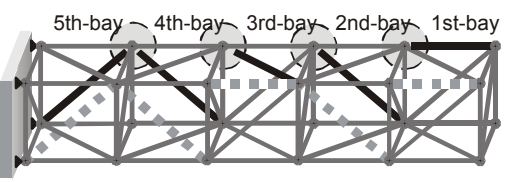

(e)

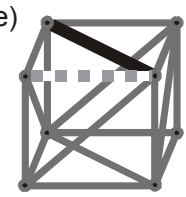

(c)

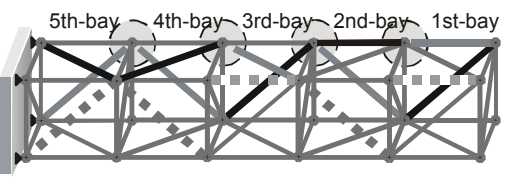

(f)

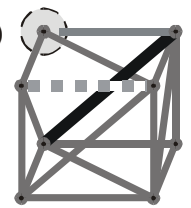

Location of the replaced element to simulate the RS

- Location of the replaced element to simulate the IC

Fig. 10 Locations of different damages applied to the truss-type structure

(a) Single damage; (b) Two damage at the same time; (c) Three damage at the same time; (d) 2nd-bay; (e) 3rd-bay; (f) 1st-bay 
Table 2 Behaviors of IMF-energy and WPT-energy

\begin{tabular}{|c|c|c|c|c|c|c|}
\hline \multirow{2}{*}{ Structure condition } & \multirow{2}{*}{ Methodology } & \multicolumn{5}{|c|}{ Damage location } \\
\hline & & First-bay & Second-bay & Third-bay & Fourth-bay & Fifth-bay \\
\hline \multirow{4}{*}{ LB } & IMF-energy & $100 \%$ & $100 \%$ & $100 \%$ & $100 \%$ & $100 \%$ \\
\hline & WPT-energy & $100 \%$ & $100 \%$ & $100 \%$ & $100 \%$ & $100 \%$ \\
\hline & MUSIC-ANN & - & - & - & - & - \\
\hline & WPT-IMF-ANN & $100 \%$ & $100 \%$ & $100 \%$ & $100 \%$ & $100 \%$ \\
\hline \multirow{4}{*}{ IC } & IMF-energy & $100 \%$ & $100 \%$ & $70 \%$ & $100 \%$ & $100 \%$ \\
\hline & WPT-energy & $100 \%$ & $100 \%$ & $70 \%$ & $100 \%$ & $100 \%$ \\
\hline & MUSIC-ANN & $100 \%$ & $100 \%$ & $100 \%$ & $100 \%$ & $100 \%$ \\
\hline & WPT-IMF-ANN & $100 \%$ & $100 \%$ & $90 \%$ & $100 \%$ & $100 \%$ \\
\hline \multirow{4}{*}{$\mathrm{RS}$} & IMF-energy & $100 \%$ & $100 \%$ & $80 \%$ & $100 \%$ & $100 \%$ \\
\hline & WPT-energy & $100 \%$ & $100 \%$ & $90 \%$ & $100 \%$ & $100 \%$ \\
\hline & MUSIC-ANN & - & - & - & - & - \\
\hline & WPT-IMF-ANN & $100 \%$ & $100 \%$ & $100 \%$ & $100 \%$ & $100 \%$ \\
\hline \multirow{4}{*}{ LB\&IC } & IMF-energy & $100 \%$ & $100 \%$ & $100 \%$ & $100 \%$ & $100 \%$ \\
\hline & WPT-energy & $90 \%$ & $100 \%$ & $100 \%$ & $100 \%$ & $100 \%$ \\
\hline & MUSIC-ANN & - & - & - & - & - \\
\hline & WPT-IMF-ANN & $100 \%$ & $100 \%$ & $100 \%$ & $100 \%$ & $100 \%$ \\
\hline \multirow{4}{*}{ LB\&RS } & IMF-energy & $100 \%$ & $100 \%$ & $100 \%$ & $100 \%$ & $100 \%$ \\
\hline & WPT-energy & $100 \%$ & $100 \%$ & $100 \%$ & $100 \%$ & $100 \%$ \\
\hline & MUSIC-ANN & - & - & - & - & - \\
\hline & WPT-IMF-ANN & $100 \%$ & $100 \%$ & $100 \%$ & $100 \%$ & $100 \%$ \\
\hline \multirow{4}{*}{ IC\&RS } & IMF-energy & $100 \%$ & $80 \%$ & $100 \%$ & $100 \%$ & $100 \%$ \\
\hline & WPT-energy & $100 \%$ & $100 \%$ & $100 \%$ & $100 \%$ & $100 \%$ \\
\hline & MUSIC-ANN & - & - & - & - & - \\
\hline & WPT-IMF-ANN & $100 \%$ & $100 \%$ & $100 \%$ & $100 \%$ & $100 \%$ \\
\hline \multirow{4}{*}{ LB\&IC\&RS } & IMF-energy & $100 \%$ & $100 \%$ & $100 \%$ & $100 \%$ & $100 \%$ \\
\hline & WPT-energy & $90 \%$ & $100 \%$ & $100 \%$ & $100 \%$ & $100 \%$ \\
\hline & MUSIC-ANN & - & - & - & - & - \\
\hline & WPT-IMF-ANN & $100 \%$ & $100 \%$ & $100 \%$ & $100 \%$ & $100 \%$ \\
\hline \multirow{4}{*}{ Healthy } & IMF-energy & & & \multirow{4}{*}{$100 \%$} & & \\
\hline & WPT-energy & & & & & \\
\hline & MUSIC-ANN & & & & & \\
\hline & WPT-IMF-ANN & & & & & \\
\hline
\end{tabular}

their combinations. In addition, the proposed methodology improves the certainty to detect and to locate structural damage; where the others proposed methodologies in the introduction section cannot. For instance, employing the proposed methodologies by Han et al. (2005), Rezaei and Taheri (2011), and Osornio-Rios et al. (2012), it is possible to have a $70 \%, 70 \%$, and $100 \%$ effectiveness to detect IC in the third-bay, respectively. On the other hand, the proposed methodology increases the detection up to $90 \%$. The methodology depicted by Osornio-Rios et al. (2012) is more efficient at detecting IC in the third-bay than the proposed methodology. However, in spite of the good results, the methodology by Osornio-Rios et al. (2012) was developed to consider the presence of single damage, not combined.

On the other hand, results shown in Fig. 7 demonstrate that it is possible to extend the proposed methodology to other structures. According to results, a single damage generates a low percent, instead, when damage is combined the percent increases; therefore, this characteristic could be used to train an ANN in order to identify the damage and to automate the process. However, this assumption needs to be studied. 


\section{Conclusions}

This paper proposes a straightforward methodology that combines WPT and empirical mode decomposition to obtain a single parameter and energy, which is used for detecting and locating different structural conditions qualitatively. The contribution of this work is that the proposed methodology can detect different single and multiply-combined damages by analyzing the vibration produced by an electrodynamic shaker, in an automatic fashion. The proposed methodology proved to be more efficient than previous methodologies where a single damage and its location are studied; besides, several damage indices are employed to identify the structure condition. The experiments carried out ascertain that the proposed methodology is very efficient and reliable for identifying and locating the three kinds of damage: LB, RS, IC, as well as their combinations, in a quantitative way with a certainty of $100 \%$. Therefore, the proposed methodology provides an easy way to locate and identify multiple-combined damage. It can be regarded as a simple and effective tool without sophisticated analysis, toward establishing a practical, reliable and more general SHM methodology. In addition, the results show that the proposed methodology could be applied to detection locations of damage in others structures by analyzing the fusion of energies, which will help to improve the performance, resistance, design, and life service of real structures.

In further work, it is necessary to investigate the possibility of automating the process in a real structure where circumstances are different. There are still some practical aspects that should be studied, i.e., the IMF- and WPT-energy-based damage identification and location in other type of structures. In addition, the monotonicity of energies should be studied in order to quantify the damage.

\section{References}

Adeli, H., 2001. Neural networks in civil engineering: 1989-2000. Computer-Aided Civil and Infrastructure Engineering, 16(2):126-142. [doi:10.1111/0885-9507.00219]

Amezquita-Sanchez, J.P., Osornio-Rios, R.A., RomeroTroncoso, R.J., Dominguez-Gonzalez, A., 2012. Hardware-software system for simulating and analyzing earthquakes applied to civil structures. Natural Hazards and Earth System Sciences, 12:61-73. [doi:10.5194/ nhess-12-61-2012]

Banks, H.T., Joyner, M.L., Wincheski, B., Winfree, W.P., 2002. Real time computational algorithms for eddy current based damage detection. Inverse Problems, 18(3):795823. [doi:10.1088/0266-5611/18/3/318]

Baptista, F.G., Filho, J.V., Inman, D.J., 2012. Real-time multisensors measurement system with temperature effects compensation for impedance-based structural health monitoring. Structural Health Monitoring, 11(2):173186. [doi:10.1177/1475921711414234]

Batis, G., Rakanta, E., 2005. Corrosion of steel reinforcement due to atmospheric pollution. Cement and Concrete Composites, 27(1):269-275. [doi:10.1016/j.cemconcomp. 2004.02.038]

Chen, B., Xu, Y.L., Qu, W.L., 2005. Evaluation of atmospheric corrosion damage to steel space structures in coastal areas. International Journal of Solids and Structures, 42(16-17):4673-4694. [doi:10.1016/j.ijsolstr.2005.02.004]

Cornwell, P., Farrar, C.R., Doebling, S.W., Sohn, H., 1999. Environmental variability of modal properties. Experimental Techniques, 23(6):45-48. [doi:10.1111/j.17471567.1999.tb01320.x]

Curadelli, R.O., Riera, J.D., Ambrosini, D., Amani, M.G., 2008. Damage detection by means of structural damping identification. Engineering Structures, 30(12):3497-3504. [doi:10.1016/j.engstruct.2008.05.024]

Doebling, S.W., Farrar, C.R., Prime, M.B., 1998. A summary review of vibration-based damage identification methods. Shock and Vibration Digest, 30:91-105.

Farrar, C.L., Worden, K., 2007. An introduction to structural health monitoring. Philosophical Transactions of the Royal Society A: Mathematical, Physical and Engineering Sciences, 365(1851):303-315. [doi:10.1098/rsta.2006. 1928]

Guo, J., Chen, Y., Sun, B.N., 2005. Experimental study of structural damage identification based on WPT and coupling NN. Journal of Zhejiang University SCIENCE A, 6(7):663-669. [doi:10.1631.jzus.2005.0663]

Han, J.G., Ren, W.X., Sun, Z.S., 2005. Wavelet packet based damage identification of beam structures. International Journal of Solids and Structures, 42(26):6610-6627. [doi:10.1016/j.jijsolstr.2005.04.031]

Hao, H., Xia, Y., 2002. Vibration-based damage detection of structures by genetic algorithm. Journal of Computing in Civil Engineering, 16(3):222-229. [doi:10.1061/(ASCE) 0887-3801(2002)16:3(222)]

Huang, N.E., Shen, Z., Long, S.R., Wu, M.C., Shih, H.H., Zheng, Q., Yen, N.C., Tung, C.C., Liu, H.H., 1998. The empirical mode decomposition and Hilbert spectrum for non-linear and non-stationary time series analysis. Proceedings of the Royal Society A: Mathematical, Physical and Engineering Sciences, 454:903-995. [doi:10.1098/ rspa.1998.0193]

Huang, Y., 2009. Advances in artificial neural networks methodological development and application. Algorithms, 2:973-1007. [doi:10.3390/algor2030973]

Jiang, X., Ma, Z.J., Ren, W.X., 2012. Crack detection from the slope of the mode shape using complex continuous wavelet transform. Computer-Aided Civil and Infrastructure Engineering, 27(3):187-201. [doi:10.1111/j.14678667.2011.00734.x]

Ko, J.M., Chak, K.K., Wang, J.Y., Ni, Y.Q., Chan, T.H., 2003. Formulation of an Uncertainty Model Relating Modal Parameters and Environmental Factors by Using Long-term 
Monitoring Data. Proceedings of Smart Structures and Materials: Smart Systems and Nondestructive Evaluation for Civil Infrastructures, San Diego, CA, USA, p.298-307.

Law, S.S., Li, X.Y., Zhu, X.Q., Chan, S.L., 2005. Structural damage detection from wavelet packet sensitivity. Engineering Structures, 27(9):1339-1348. [doi:10.1016/j. engstruct.2005.03.014]

Lei, Y., Jiang, Y., Xu, Z., 2012. Structural damage detection with limited input and output measurement signals. $M e$ chanical Systems and Signal Processing, 28:229-243. [doi:10.1016/j.ymssp.2011.07.026]

Li, H., Huang, Y., Chen, W.L., Ma, M.L., Tao, D.W., Ou, J.P., 2011. Estimation and warning of fatigue damage of FRP stay cables based on acoustic emission techniques and fractal theory. Computer-Aided Civil and Infrastructure Engineering, 26(7):500-512. [doi:10.1111/j.1467-8667. 2010.00713.x]

Mao, Y., Que, P., 2006. Application of Hilbert-Huang signal processing to ultrasonic non-destructive testing of oil pipelines. Journal of Zhejiang University SCIENCE A, 7(2):130-134. [doi:10.1631/jzus.2006.A0130]

Mehrjoo, M., Khaji, N., Moharrami, H., Bahreininejad, A., 2008. Damage detection of truss bridge joints using artificial neural networks. Expert Systems with Application, 35(3):1122-1131. [doi:10.1016/j.eswa.2007.08.008]

Meruane, V., Heylen, W., 2012. Structural damage assessment under varying temperature conditions. Structural Health Monitoring, 11(3):345-357. [doi:10.1177/14759217114 19995]

Nishikawa, T., Yoshida, J., Sugiyama, T., Fujino, Y., 2012. Concrete crack detection by multiple sequential image filtering. Computer-Aided Civil and Infrastructure Engineering, 27(1):29-47. [doi:10.1111/j.1467-8667.2011. 00716.x]

Osornio-Rios, R.A., Amezquita-Sanchez, J.P., RomeroTroncoso, R.J., Garcia-Perez, A., 2012. MUSIC-ANN analysis for locating structural damages in a truss-type structure by means of vibrations. Computer-Aided Civil and Infrastructure Engineering, 27(9):687-698. [doi:10. 1111/j.1467-8667.2012.00777.x]

Peeters, B., de Roeck, G., 2001. One-year monitoring of the Z24 Bridge: environmental effects versus damage events. Earthquake Engineering \& Structural Dynamics, 30(2): 149-171. [doi:10.1002/1096-9845(200102)30:2]

Razi, P., Esmaeel, R.A., Taheri, F., 2011. Application of a robust vibration-based non-destructive method for detection of fatigue cracks in structures. Smart Materials and Structures, 20(11):1-12. [doi:10.1088/0964-1726/20/11/ 115017]

Ren, W.X., Sun, Z.S., 2008. Structural damage identification by using wavelet entropy. Engineering Structures, 30(10): 2840-2849. [doi:10.1016/j.engstruct.2008.03.013]

Rezaei, D., Taheri, F., 2009. Experimental validation of a novel structural damage detection method based on empirical mode decomposition. Smart Materials and Structures, 18(4):045004. [doi:10.1088/0964-1726/18/4/045004]

Rezaei, D., Taheri, F., 2011. Damage identification in beams using empirical mode decomposition. Structural Health Monitoring, 10(3):261-274. [doi:10.1177/1475921710 373298]

Sayyad, F.B., Kumar, B., 2011. Theoretical and experimental study for identification of crack in cantilever beam by measurement of natural frequencies. Journal of Vibration and Control, 17(8):1235-1240. [doi:10.1177/107 7546310384005]

Shih, J.K.C., Delpak, R., Hu, C.W., Plassmann, P., Wawrzynek, A., Kogut, M., 2000. Thermographic nondestructive testing damage detection for metals and cementitious materials. Journal on Imaging Sciences, 48:33-43.

Taha, M.M.R., 2010. A neural-wavelet technique for damage identification in the ASCE benchmark structure using phase II experimental data. Advances in Civil Engineering, 2010:675927. [doi:10.1155/2010/675927]

Talebinejad, I., Fischer, C., Ansari, F., 2011. Numerical evaluation of vibration-based methods for damage assessment of cable-stayed bridges. Computer-Aided Civil and Infrastructure Engineering, 26(3):239-251. [doi:10. 1111/j.1467-8667.2010.00684.x]

Tan, L., Wang, L., 2011. Oversampling technique for obtaining higher order derivative of low-frequency signals. IEEE Transactions on Instrumentation and Measurement, 60(11):3677-3684. [doi:10.1109/TIM.2011.2135050]

Umesha, P.K., Ravichandran, R., Sivasubramanian, K., 2009. Crack detection and quantification in beams using wavelets. Computer-Aided Civil and Infrastructure Engineering, 24(8):593-607. [doi:10.1111/j.1467-8667.2009. 00618.x]

Voigt, T., Akkaya. Y., Shah, S., 2003. Determination of early age mortar and concrete strength by ultrasonic wave reflections. Journal of Materials in Civil Engineering, 15(3):247-254. [doi:10.1061/(ASCE)0899-1561(2003)15: $3(247)]$

Vossoughi, F., Ostertag, C.P., Monteiro, P.J.M., Albert, R.D., 2007. Damage characterization of concrete panels due to impact loading by motionless X-ray laminography. Journal of Materials Science, 42(9):3280-3285. [doi:10. 1007/s10853-006-0731-2]

Wang, G.P., Hong, Y., Hong, D.P., Kim, Y.M., 2008. Damage detection of truss-like structures using wavelet transforms. Modern Physics Letters B, 22(11):1165-1170. [doi:10. 1142/S0217984908016017]

Wang, J., Chen, L., 2005. Damage detection of frames using the increment of lateral displacement change. Journal of Zhejiang University SCIENCE A, 6(3):202-212. [doi:10. 1631/jzus.2005.A0202]

Wang, X., Hu, N., Fukunaga, H., Yao, Z.H., 2001. Structural damage identification using static test data and changes in frequencies. Engineering Structures, 23(6):610-621. [doi:10.1016/S0141-0296(00)00086-9]

Xiang, J., Liang, M., 2012. Wavelet-based detection of beam cracks using modal shape and frequency measurements. Computer-Aided Civil and Infrastructure Engineering, 27(6):439-454. [doi:10.1111/j.1467-8667.2012.00760.x]

Yan, G., Dyke, S.J., Irfanoglu, A., 2012. Experimental validation of a damage detection approach on a full-scale highway sign support truss. Mechanical Systems and Signal Processing, 28:195-211. [doi:10.1016/j.ymssp. 2011.10.008]

Yang, Q.W., Sun, B.X., 2011. Structural damage localization and quantification using static test data. Structural Health Monitoring, 10(4):381-389. [doi:10.1177/147592 1710379517] 